\title{
Improving Small Weed Seeds Viability Assessment Using Tetrazolium Test
}

\author{
Fernanda B. G. Anghinoni ${ }^{1}$, Alessandro L. Braccini ${ }^{2}$, Guilherme Anghinoni ${ }^{1}$, Pablo Jourdan ${ }^{3}$, \\ Guilherme B. P. Braz ${ }^{4}$, Alfredo J. P. Albrecht ${ }^{5} \&$ Rubem S. de O. Junior ${ }^{2}$ \\ ${ }^{1}$ Postgraduate Program in Agronomy, State University of Maringa, Maringá, Paraná State, Brazil \\ ${ }^{2}$ Department of Agronomy, State University of Maringa, Maringa, Paraná State, Brazil \\ ${ }^{3}$ Department of Horticulture and Crop Science, The Ohio State University, Columbus, OH, USA \\ ${ }^{4}$ Department of Agronomy, University of Rio Verde, Rio Verde, Goiás, Brazil \\ ${ }^{5}$ Federal University of Paraná, Palotina, Paraná, Brazil \\ Correspondence: Fernanda B. G. Anghinoni, Postgraduate Program in Agronomy, State University of Maringa, \\ Av. Colombo 5790, CEP 87020-900, Maringa, Paraná State, Brazil. E-mail: ferbrunettag@gmail.com
}

Received: June 24, 2019

doi:10.5539/jas.v11n15p209
Accepted: July 29, 2019 Online Published: September 15, 2019

URL: https://doi.org/10.5539/jas.v11n15p209

The research is financed by the Brazilian National Council for Research and Development (CNPq).

\begin{abstract}
Tetrazolium testing in small seeds demands difficult and longstanding procedures, such as the embryo exposure by seeds section and the seeds pre-preparation. This study aims to access the viability of small seeds using the Tetrazolium test (TZ) without seeds sectioning, resulting in quicker, cheaper and precise measurements. Non-sectioned seeds of Conyza sumatrensis, Bidens pilosa and Digitaria insularis were put in contact with the tetrazolium solution during $0,12,24,48,72,144,216,288,360,432$ and $504 \mathrm{~h}$ to obtain the seeds coloring percentage in each time. When possible, the seeds coloring percentages were compared to seeds viability, obtained by the literature standard tetrazolium methodology (STZ), and with seeds germination. The proposed methodology (TZM) was cheaper and less laborious than the methodologies frequently used for weed seeds viability estimation, and provided rapid and reliable seeds viability estimations for weed species with small seeds within $24 \mathrm{~h}$ for Digitaria insularis and Bidens pilosa, and $48 \mathrm{~h}$ for Conyza sumatrensis.
\end{abstract}

Keywords: Bidens pilosa, Conyza sumatrensis, Digitaria insularis, fast test and weed science

\section{Introduction}

Weeds aggressiveness characteristics highly contributes to plants interference processes, impairing crops development. A part of this characteristic is related to seeds production and physiological behavior, including the high number of propagules formed, dissemination mechanisms and seed dormancy, which enable asynchronous germination (Cauwer et al., 2014). Weeds producing thousands seeds per plants are often found, resulting in increased difficulties on their control within farming areas and increasing the soil seed bank (SSB). SSB is a source of viable weed seeds, located within or on the soil body, potentially capable of infesting croplands (Hosseini et al., 2014).

As an example, Conyza sp. seeds exhibit increased germination levels on the beginning of autumn or spring (Buhler \& Owen, 1997; Holm et al., 1997, Regehr \& Bazzazn, 1979), but its germination does not stop during the year. Digitaria sp. and Bidens sp. species are spread in tropical, subtropical and temperate regions of the world (Watson \& Dallwitz, 1992), and its seeds may exhibit dormancy (Souza et al., 2009). Therefore, the assessment of seeds viability on the SSB, as well as those still attached to the plant, is critical for inferring about dissemination and infestation potentials of those weeds.

The most common methods used in seeds viability assessment are top-of-paper, standard paper germination (SG), germination in sand and the agar method (Rao et al., 2006). Nevertheless, those methods may not be efficient in weed seeds viability estimation due to seeds manipulation difficulties and temperature, air humidity, light and test duration specific requirements, resulting in tests lasting days or months (Taylorson, 1987; McIvor \& 
Howden, 2000; Koger et al., 2004; ISTA, 2005). The SG is the most common among those, but does not provide the total seeds germination potential precisely because of seeds dormancy (Taylorson, 1970). Furthermore, seeds identified as viable by those methods cannot be used in posterior studies, since their germination makes them unfeasible.

Another problem related to the conventional germination tests used for weed seeds comes from their decreased sanitary quality. Total loss of a replication or an entire test due to fungi or bacteria attack are common. It happens because weed seeds of the SSB exhibit increased longevity (Burnside et al., 1996), which favors their contamination by pathogens or mechanical damages incidence. Tetrazolium test (TZ) avoids those problems caused by seeds contamination (Thorpe \& Kaye, 2008), but has not been frequently used for small seeds testing, such as weeds. Due to its small size, weed seeds represent a challenge for TZ performing, once that this methodology requires embryo exposure to the tetrazolium salt solution with posterior evaluation of the sectioned seeds, which is a difficult task in such small seeds. Nevertheless, improvements on the TZ method for evaluation of small seeds would result in costs and time reduction, as well as increase accuracy in weed seeds viability assessment.

For Conyza sp. species, no TZ methodology was found to be described in literature so far. The methodology proposed by the International Seed Testing Association (Moore, 1985) for monocots using TZ is laborious, and therefore non-used. It suggests that seeds must be maintained soaked in water for 6-18 hours and sectioned in halves afterwards for posterior immersion in the tetrazolium solution for $48 \mathrm{~h}$, resulting in 70 hours from the beginning to the end of the test. In addition to the duration, the sectioning of such small seeds as of Conyza sp. increases the difficulties of the test.

Possible contributions through improvements on small seeds viability testing are related to the identification of dormancy mechanisms or seed damages occurrence, including dead seeds. Those improvements would allow to isolate effects in studies of herbicides performance, when applied in pre-emergence. With the real physiological state of the weed seed, it would be possible to comprehend if the non-emergence of the plantlet was because of a previous physiological condition of the seed or due to the herbicide control effect. It would consequently result in less overestimations on herbicides molecules effects, as well as enable decreases on the use of low quality weed seeds in experiments. Adaptions on the TZ methodology that eliminate the need of seeds sectioning for viability evaluation may result in a simpler and more useful test. Our hypothesis is that it is possible to obtain a faster, cheaper and simpler TZ method for C. sumatrensis, B. pilosa and D. insularis seeds than those already described in literature. On this context, the objective of this study is to propose adaptions to the TZ test for Digitaria insularis and Conyza sumatrensis seeds that may properly and easily estimate their viability, and to compare the results obtained with the proposed method with the ones obtained with the standard and available TZ methodologies and SG.

\section{Method}

\subsection{Seeds Collection}

Seeds of B. pilosa, D. insularis and C. sumatrensis, growing in commercial fields at Engenheiro Coelho, São Paulo State, Brazil (22 $29^{\prime} 18^{\prime \prime}$ S; $\left.47^{\circ} 12^{\prime} 57^{\prime \prime} \mathrm{W}\right)$, in September, 2017, were collected by gently rubbing the mature inflorescences of six plants each. The harvested seeds were stored during 30 days after harvest, at $25^{\circ} \mathrm{C}$ and $60 \%$ air relative humidity, until the tests were conducted. The mass of a thousand seeds for B. pilosa, D. insularis and C. sumatrensis were $1.60 \mathrm{~g}, 0.80 \mathrm{~g}$ and $0.07 \mathrm{~g}$, respectively.

\subsection{Seeds Testing}

All species studied were submitted to the standard germination test (SG) on germination paper, while the methodology proposed by Moore (1985) to evaluate seeds viability using TZ (STZ), was compared with the TZ methodology proposed herein (TZM) for Bidens spp. and Digitaria spp., and followed procedures described in literature for each species. No standard method was found in literature for Conyza spp., and therefore no STZ was performed for this species.

For the STZ, seeds were submerged in water for $12 \mathrm{~h}$, and after this period were cut in two halves and kept in tetrazolium solution $(0.1 \%)$ up to $48 \mathrm{~h}$ at $30{ }^{\circ} \mathrm{C}$. After that, seeds with red stained embryo were considered viable.

SG tests were performed in five replications of 50 seeds each, within plastic boxes, and kept in artificially illuminated incubators (model TE-4000, Tecnal Company). These incubators are equipped with three lamp pairs in each tray level, and released $100 \mu \mathrm{mol}$ photons $/\left(\mathrm{m}^{2} \mathrm{~s}^{-1}\right)$ of light in each level. The gerboxes received $3 \mathrm{~mL}$ of distilled water each, at the beginning of the test, and the water was refilled when necessary. The seeds of $D$. 
insularis were exposed to specific photoperiod (12 h under dark and $12 \mathrm{~h}$ under light) and stable temperature of $35^{\circ} \mathrm{C}$. C. sumatrensis seeds were maintained under constant $20^{\circ} \mathrm{C}$ temperature and same photoperiod used for $D$. insularis, as established in $\mathrm{Wu}$ et al. (2007). B. pilosa seeds were incubated at $25^{\circ} \mathrm{C}$ for $12 \mathrm{~h}$ in the dark and at $30{ }^{\circ} \mathrm{C}$ for $12 \mathrm{~h}$ under light (Reddy \& Singh, 1992). The seeds were considered germinated when the radicle protrusion through the tegument was visible (Chivinge, 1996; Brasil, 2009). The number of germinated seeds was obtained in $0,12,24,48,72,144,216,288,360,432$ and $504 \mathrm{~h}$ after the test beginning.

The TZM for each species are described as follows:

\subsubsection{C. sumatrensis and B. pilosa}

Five replications of 50 C. sumatrensis and B. pilosa seeds were placed in individual Eppendorf tubes $(20 \mathrm{~mL})$ containing $10 \mathrm{~mL}$ of Tetrazolium solution $(0.1 \%$-w/v), covered with aluminum foil for protection against light, and exposed to $40{ }^{\circ} \mathrm{C}$ for $504 \mathrm{~h}$. Every $12 \mathrm{~h}$ the seeds were removed from the TZ solution, in a low light environment, and examined with a microscope. Seeds that were colored in red or pink were considered viable, while the ones not colored were considered dead (Moore, 1985; Tesnier et al., 2002; Figures 1 and 2). Seeds considered viable were discarded after counting, and the ones not colored were placed in fresh TZ solution after each evaluation. C. sumatrensis seeds are very small, and the mean weight of a single seed is around $0.072 \mathrm{~g}$. The cover tissue of C. sumatrensis represents around $15 \%$ of this mass and $85 \%$ corresponds to the embryo (Fenner, 1983). As the external part of the seed is translucent, it is possible to identify the tetrazolium coloring without cutting open C. sumatrensis seeds (Figure 1). For B. pilosa, seeds with reddish or pink embryo were also considered viable, while the ones not colored were considered dead, as observed in Figure 2. In this case, the embryo is visible on the cypselas cracks, uniformly present after seeds soaking. When not visible, the embryo may be exposed when removing the cypsela, which is easily opened by the touch after soaked.

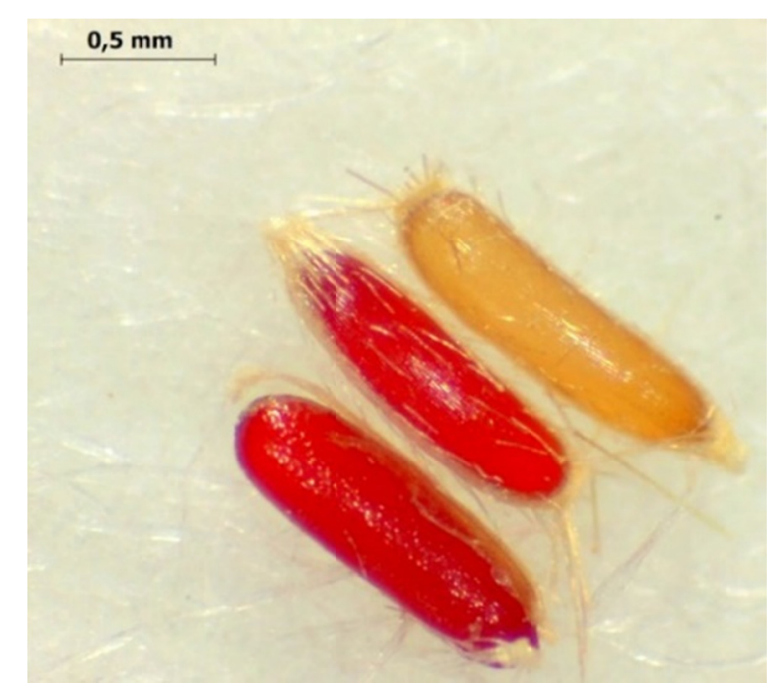

Figure 1. Tetrazolium staining of Conyza sumatrensis seeds, with TZM. Red-stained seeds are considered viable or metabolically active, and therefore potentially capable of germination, and the uncolored seed

(top-right) is considered dead 


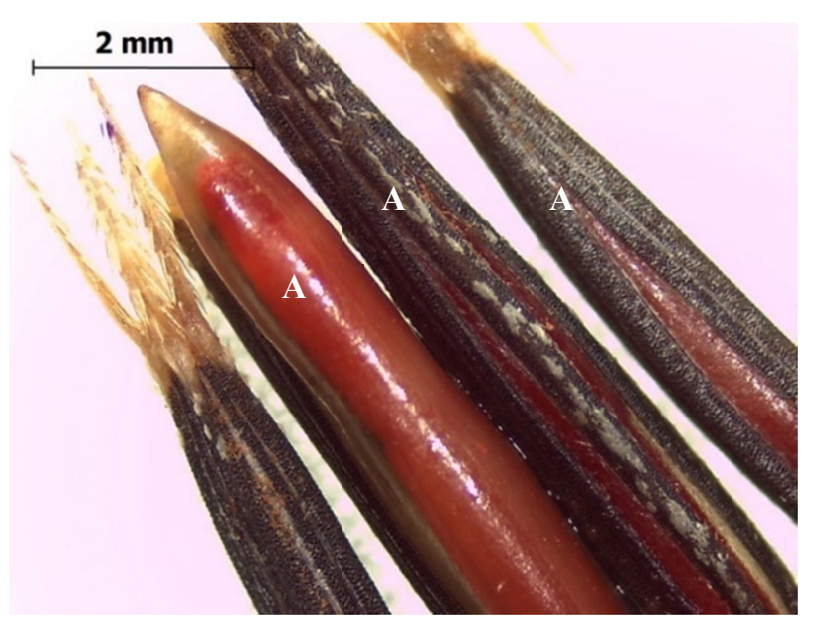

Figure 2. Tetrazolium staining of Bidens pilosa seeds, with TZM. Red-stained seeds (A) are considered viable or metabolically active, and therefore capable of germination, while non-colored seeds are considered dead. The arrows indicate the red-stained tissues

The evaluation of C. sumatrensis and B. pilosa seeds coloring was performed at same moments as established for the SG counting.

\subsubsection{D. insularis}

D. insularis seeds carry specific structures called palea and lemma that may interfere with translocation of the Tetrazolium salt solution into the seeds, affecting the coloring of the seed tissue. Therefore, as proposed on the international rules for seed analysis (Moore, 1985), these seeds must be cut in half for the analysis. In this study, we explore the utilization of uncut $D$. insularis seeds for the TZ test, after removal of the palea and lemma structures from each one. In this case the palea and lemma of 250 seeds were removed, and five replications of 50 seeds each were immediately incubated in $0.1 \%$ Tetrazolium salt solution, as in the other two species. Evaluations were conducted each $12 \mathrm{~h}$ and the seeds that presented reddish or pink embryo tissues were considered viable, and the ones not colored were considered dead; the endosperm of these grass seeds does not contain living tissue (Figure 3 ). The evaluation of $D$. insularis seeds coloring was performed at same moments as in SG evaluations.
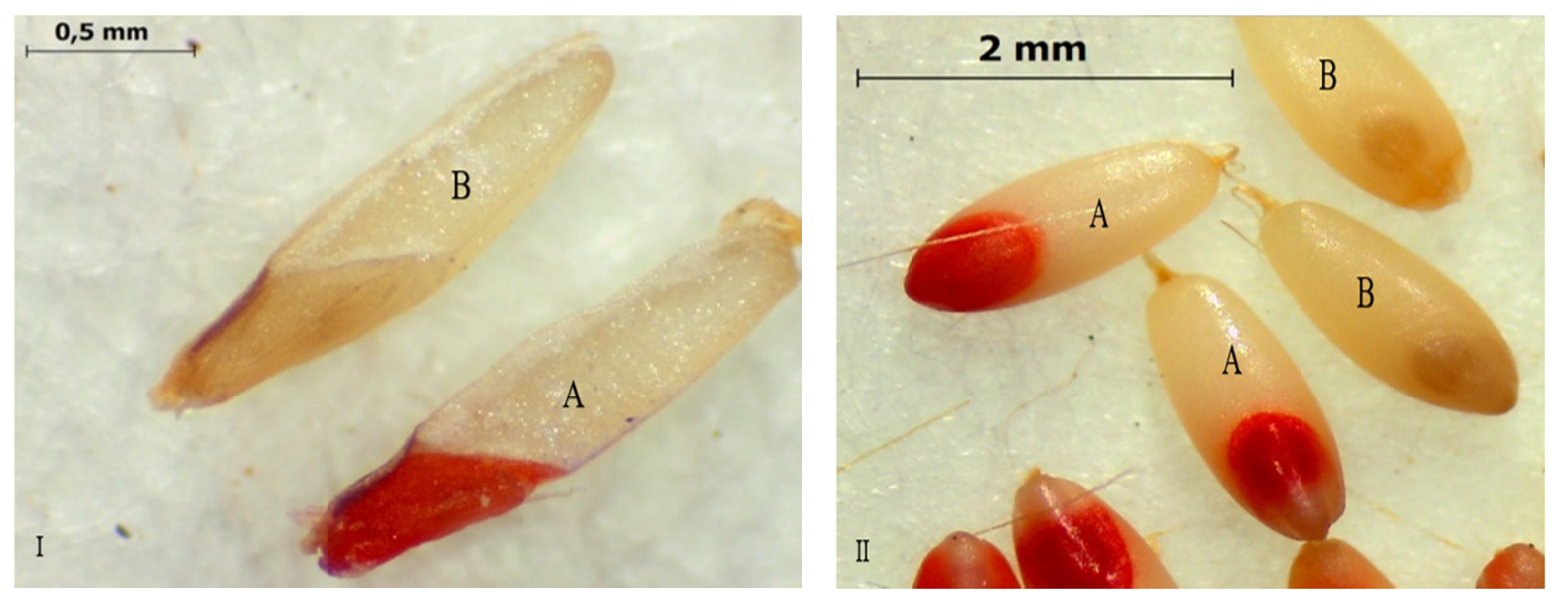

Figure 3. Tetrazolium staining of Digitaria insularis seeds. I: sectioned seeds (STZ) and II: uncut seeds (TZM). Red-stained (A) seeds are considered viable or metabolically active, and therefore capable of germination.

Uncolored seeds (B) were considered dead

\subsection{Statistical Analysis}

Means were compared by the mean confidence interval $(\mathrm{p}<0.05)$, as described in Payton et al. (2000). 


\section{Results and Discussion}

Seeds viability of $C$. sumatrensis and B. pilosa, determined by TZM, were compared to the STZ method, proposed by Moore (1985), and SG of all three species studied are presented in Figures 4-6. Seeds viability and germination, obtained by the TZM and SG tests, were similar for D. insularis and C. sumatrensis, as well as STZ was similar to SG for D. insularis. B. pilosa had less germinated seeds in comparison to the number of viable seeds, obtained by SG and TZM, respectively. This difference in behavior indicates that $D$. insularis and $C$. sumatrensis seeds lacked dormancy, once their viability and germination values were statistically not different, highlighted by the plateaus obtained for percentage of colored seeds by the TZM test and percentage of seeds germinated on the SG test (Figures 4 and 6). The difference between seeds viability and germination of $B$. pilosa is probably an indication of seeds dormancy. The estimation of the overall seed viability by using the SG test may therefore be highly influenced by dormancy, and provide inaccurate results regarding weeds infestation potential. The methodology proposed herein may therefore provide reliable data regarding weed seeds viability.

Figure 4 demonstrates that, after $24 \mathrm{~h}$ of seeds exposure to tetrazolium salt solution, there was a stable number of viable $B$. pilos $a$ seeds until the end of the test, while the first colored seeds were identified within $12 \mathrm{~h}$ after the TZM test started. The SG test on the other hand, only reached germination stability after $280 \mathrm{~h}$, indicating that the TZM test was faster (11 times) to establish the viability potential than the SG test took to reach seeds germination of B. pilosa. As long as the number of seeds identified as viable by the TZM test reached stabilization within $24 \mathrm{~h}$, we understand that this period was sufficient to be considered as a standard for future evaluations of $B$. pilosa seeds viability by the proposed TZM test. From the total amount of $B$. pilosa seeds tested, $78 \%$ were identified as viable by the TZM test (Figure 4), meaning that $22 \%$ of B. pilosa seeds were dead. From the total amount of viable $B$. pilosa seeds, only $23 \%$ were capable to germinate $(18 \%$ of the total number of seeds), and therefore $77 \%$ of the viable $B$. pilosa seeds were dormant, as long as they were viable, but did not germinate under optimal conditions.

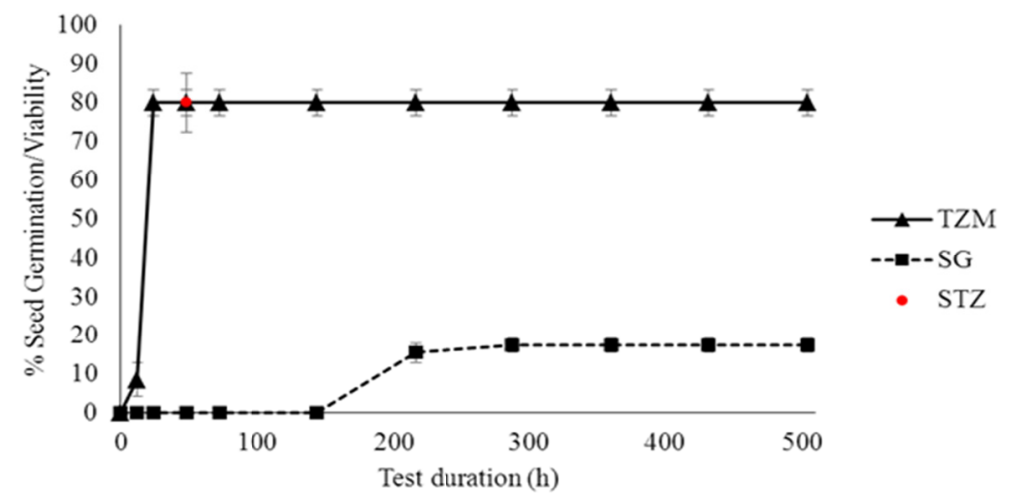

Figure 4. Comparison of two methods to estimate Bidens pilosa seeds viability. The ordinates axis refers to the percentage of germinated seeds in the standard germination test (SG) and percentage of seeds colored by the tetrazolium test (TZ), for Bidens pilosa seeds, and the abscissas axis refers to the time in which TZ and SG were taken account. The bars refer to the mean confidence interval $(\mathrm{p}<0.05)$

The TZ test was used to evaluate seeds overall viability, and therefore its germination potential. The SG, on the other hand, provided a realistic indication of the seedling production potential of weed seeds within $500 \mathrm{~h}$ after proper environmental conditions for seeds germination were reached. Seed dormancy appeared to play an important role on the differences between TZM and SG results of B. pilosa, causing asynchronous seeds germination and misrepresentation of the total germination capacity of the weed seeds lot by the SG test.

Figure 5 demonstrates that the stabilization of $C$. sumatrensis seeds viability, identified by the TZM test, was observed at first within $48 \mathrm{~h}$, while seeds germination took 3.5 times more to reach stabilization $(216 \mathrm{~h})$. The TZM test identified the first viable seeds within $12 \mathrm{~h}$ after the test beginning, and increased the number of viable seeds identified by the method in $24 \mathrm{~h}$. As no other methodology of C. sumatrensis seeds viability using TZ was identified by the authors in literature, it can be stated that the results expose sufficient information to establish 46 $\mathrm{h}$ as a standard period in future evaluations of $C$. sumatrensis seeds viability using TZM, once it provided the maximum number of viable seeds in the shortest term. 


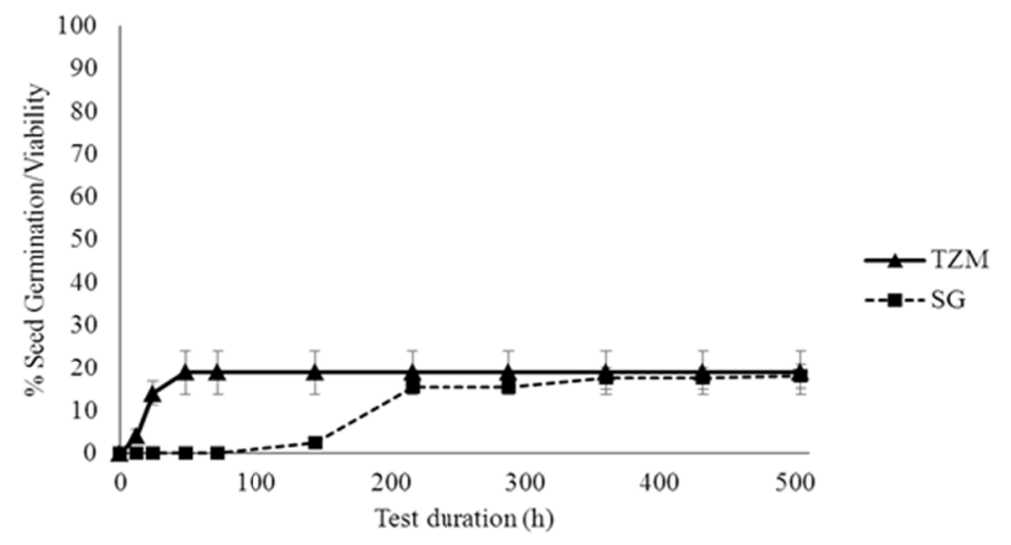

Figure 5. Comparison of two methods to estimate Conyza sumatrensis seeds viability. The ordinates axis refers to the percentage of germinated seeds in the standard germination test (SG) and percentage of seeds colored by the tetrazolium test (TZ), for Conyza sumatrensis seeds, and the abscissas axis refers to the time in which TZ and $\mathrm{SG}$ were taken account. The bars refer to the mean confidence interval $(\mathrm{p}<0.05)$

There was no difference between seeds viability and germination of $C$. sumatrensis. This is an effect of low or inexistent seeds dormancy incidence and an indication that collected seeds of this species were mature and that the germination methodology was well fitted to represent seeds viability of $C$. sumatrensis (Buhler \& Hoffman, 1999). The herbicides selectivity testing of Conyza sp. is widely performed in weed science, once the selection of herbicide resistant populations (Weed Science, 2018) has increased complexity of its chemical control. Therefore, a quick and easy TZ test that does not impairs seeds germination may provide significant help in fast detection of viability of these populations.

Figure 6 demonstrates the SG, STZ and TZM tests results for D. insularis. Within $216 \mathrm{~h}$, the beginning of seeds germination process was identified by the SG test, reaching a stable level at the same time. In turn, the TZM test demonstrated that $16 \%$ of the seeds tested were colored in the first $12 \mathrm{~h}$, reaching a stable plateau in the first $24 \mathrm{~h}$, with $90 \%$ of the seeds colored in red and identified as viable. TZM and SG results obtained after seeds viability and germination stabilization, respectively, were not significantly different from the STZ test, indicating that seeds dormancy was probably absent in this seeds lot and that SG testing of $D$. insularis is reliable to study seeds viability, in contrast with $B$. pilosa. Even though, the TZM test was eight times faster than the SG test, permitting inferences about $D$. insularis seeds viability within $24 \mathrm{~h}$.

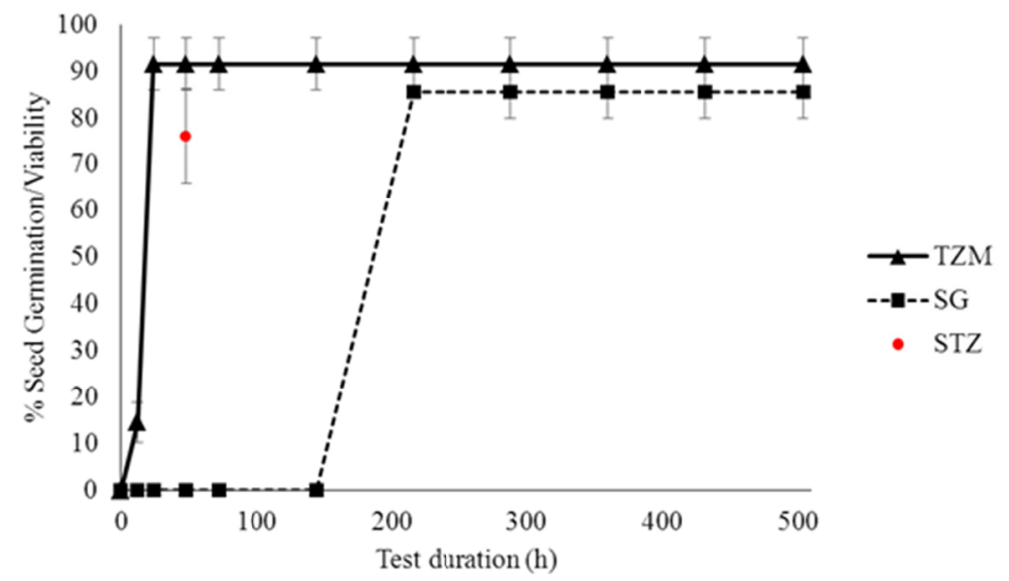

Figure 6. Comparison of two methods to estimate Digitaria insularis seeds viability. The ordinates axis refers to the percentage of germinated seeds in the standard germination test (SG) and percentage of seeds colored by the tetrazolium test (TZ), for Digitaria insularis seeds, and the abscissas axis refers to the time in which TZ and SG were taken account. The bars refer to the mean confidence interval $(\mathrm{p}<0.05)$ 
There is a limited number of studies regarding $D$. insularis seeds quality evaluation and germination tests. Considering that, methodologies were adapted to proper representation of germination levels, with different temperatures and photoperiods according to the seeds origin site. Varying temperatures from $20-30{ }^{\circ} \mathrm{C}, 20-35{ }^{\circ} \mathrm{C}$ and $15-35^{\circ} \mathrm{C}$ with a $16-8 \mathrm{~h}$ of light per day are described as more suitable than constant temperature and light periods for studies involving Digitaria spp. (Mondo et al., 2010; Mendonça et al., 2014). Mondo et al. (2010) even question the light incidence requirements for D. insularis germination, while Mendonça et al. (2014) describes dependence of seeds germination in relation to the photoperiod.

Results obtained by the STZ and TZM tests for B. pilosa and D. insularis, in Figs. 4 and 6, indicate that the TZM test permitted proper inference on the seeds viability potential. The TZM methodology proposed herein aims to facilitate seeds viability determination, using a standardized methodology without cutting seeds, as seen in most weed seeds evaluation methodologies, and without any treatment to break dormancy. Furthermore, the test provided fast viability results $(24-48 \mathrm{~h})$ of $B$. pilosa, C. sumatrensis and D. insularis seeds. With that, we expect that studies involving weed seeds may be improved and facilitated, since herbicide resistance is expected to be an increasingly problematic issue in cropping fields (Peterson, Collavo, Ovejero, Shivrain, \& Walsh, 2018).

The exposed results indicate that there is a great potential on this test application in studies involving weeds with small seeds. Studies regarding effects of pre-emergent herbicides on weed seeds may be improved by a quick and less laborious TZ test for weeds with small seeds, once the effect of the treatment may then be separated from the effect of seeds dormancy. The methodology proposed herein allows rapid and reliable results regarding seeds viability.

\section{Conclusion}

The proposed methodology for the tetrazolium test was rapid and reliable for small seeds viability estimation. The test provided $D$. insularis and B. pilosa seeds viability within $24 \mathrm{~h}$, while $C$. sumatrensis seeds viability was obtained within $48 \mathrm{~h}$. Besides being faster than the standard paper germination test, and simpler than the STZ test proposed for $D$. insularis and B. pilosa, the TZM test proposed herein did not cause damage to the seeds, enabling its later use in field trials, generating results that do not carry seeds dormancy influences.

\section{References}

American Psychological Association. (1972). Ethical standards of psychologists. Washington, DC: American Psychological Association.

Brasil, Ministério da Agricultura, Pecuária e Abastecimento. (2009). Regras para análise de sementes. Secretaria de Defesa Agropecuária. Brasília: MAPA/ACS.

Buhler, D. D., \& Hoffman, M. L. (1999). Andersen's guide to practical methods of propagating weeds \& other plants (p. 248). Weed Science Society of America, Lawrence, KS.

Buhler, D. D., \& Owen, M. D. K. (1997). Emergence and survival of horseweed (Conyza canadensis). Weed Sci., 45, 98-101. https://doi.org/10.1017/S0043174500092535

Burnside, O. C., Wilson, R. G., Weisberg, S., \& Hubbard, K. G. (1996). Seed longevity of 41 weed species buried 17 years in eastern and western Nebraska. Weed Sci., 44(1), 74-86. https://doi.org/10.1017/S004317 4500093589

Cauwer, B., Devos, R., Claerhout, S., Bulcke, R., \& Reheul, D. (2014). Seed dormancy, germination, emergence and seed longevity in Galinsoga parviflora and G. quadriradiata. Weed Research, 54, 38-47. https://doi.org/ $10.1111 /$ wre. 12055

Chivinge, O. A. (1966). Studies on the germination and seedling emergence of Bidens pilosa and its response to fertilizer application. Trans. Zimb. Scient. Assoc., 70, 1-5.

Fenner, M. (1983). Relationships between seed weight, ash content and seedling growth in twenty-four species of Compositae. New Phytol, 95, 697-706. https://doi.org/10.1111/j.1469-8137.1983.tb03533.x

Holm, L. J., Doll, E., Holm, P. J., \& Herberger, J. (1997). World Weeds, Natural Histories and Distribution (pp. 226-235). New York: J Wiley.

Hosseini, P., Karimi, H., Babaei, S., Mashhadi, H. R., \& Oveisi, M. (2014). Weed seed bank as affected by crop rotation and disturbance. Crop Protection, 64, 1-6. https://doi.org/10.1016/j.cropro.2014.05.022

ISTA (International Seed Testing Association). (2005). International Rules for Seed Testing. International Seed Testing Association, Bassersdorf, Switzerland. 
Koger, C. H., Reddy, K. N., \& Poston, D. H. (2004). Factors affecting seed germination, seedling emergence, and survival of texasweed (Caperonia palustris). Weed Science, 52(6), 989-995. https://doi.org/10.1614/ WS-03-139R2

Mcivor, J. G., \& Howden, S. M. (2000). Dormancy and germination characteristics of herbaceous species in the seasonally dry tropics of northern Australia. Austr. Ecol., 25(3), 214-222. https://doi.org/10.1046/ j.1442-9993.2000.01026.x

Mendonça, G. S. De, Martins, C. C., Martins, D., \& Costa, N. V. da. (2014). Ecofisiologia da germinação de sementes de Digitaria insularis (L.) Fedde. Rev. Ciênc. Agron, 45(4). https://doi.org/10.1590/S1806-66902 014000400021

Mondo, V. H. Z., Carvalho, S. J. P., Dias, A. C. R., \& Marcos Filho, J. (2010). Light and temperature effects on the seed germination of four Digitaria weed species. Rev Bras Sem, 32, 131-137. https://doi.org/10.1590/ S0101-31222010000100015

Moore, R. P. (1985). Handbook on Tetrazolium testing (2nd ed., p. 99). International Seed Testing Association. Zurich.

Payton, M. E., Miller, A. E., \& Raun, W. R. (2000). Testing Statistical Hypotesis using standard error bars and confidence intervals. Communications in Soil Science and Plant Analysis, 31(5-6). https://doi.org/10.1080/ 00103620009370458

Peterson, M. A., Collavo, A., Ovejero, R., Shivrain, V., \& Walsh, M. J. (2018). The challenge of herbicide resistance around the world: A current summary. Pest Manag Sci, 74(10), 2246-2259. https://doi.org/ $10.1002 /$ ps. 4821

Rao, N. K., Hanson, J., Dulloo, M. E., Ghosh, K., Nowell, D., \& Larinde, M. (2006). Manual of seed handling in genebanks. Rome, IT: Bioversity International.

Reddy, K. N., \& Singh, M. (1992). Germination and Emergence of Hairy Beggarticks (B. pilosa). Weed Science, 40, 195-199. https://doi.org/10.1017/S0043174500057210

Regehr, D. L., \& Bazzaz, F. A. (1976). Low temperature photosynthesis in successional winter annuals. Ecology, 57, 1297-1303. https://doi.org/10.2307/1935054

Souza, M. C., Pitelli, R. A., Simi, L. D., \& Oliveira, M. C. J. (2009). Seed emergence of Bidens pilosa at different sowing depths. PlantaDaninha, 27(1), 29-34. https://doi.org/10.1590/S0100-83582009000100005

Taylorson, R. B. (1987). Environmental and chemical manipulation of weed seed dormancy. Rev. Weed Sci, 3, 135-154.

Tesnier, K., Strookman-Donkers, H. M., Van Pijlen, J. G., Van Der Geest, A. H. M., Bino, R. J., \& Groot, S. P. C. (2002). A controlled deterioration test for Arabidopsis thaliana reveals genetic variation in seed quality. Seed Science \& Technology, 30, 149-165.

Thorpe, A. S., \& Kaye, T. N. (2008). Conservation Research in the Leslie Gulch ACEC: Population monitoring and seed bank dynamics in Senecioertterae. Final Report. Prepared by Institute for Applied Ecology for Vale District BLM.

Watson, L., \& Dallwitz, M. J. (1992). The Grass Genera of the world (p. 1038). Wallingford: CAB International.

Weed Science. (2018). Resistant weeds by species and country. Herbicide Resistant Horseweed Globally.

Wu, H., Walker, W., Rollin, M. J., Tan, D. K. Y., Robinson, G., \& Werth, J. (2007). Germination, persistence, and emergence of flaxleaf fleabane (Conyza bonariensis [L.] Cronquist). Weed Biology and Management, 7(3), 192-199. https://doi.org/10.1111/j.1445-6664.2007.00256.x

\section{Copyrights}

Copyright for this article is retained by the author(s), with first publication rights granted to the journal.

This is an open-access article distributed under the terms and conditions of the Creative Commons Attribution license (http://creativecommons.org/licenses/by/4.0/). 